\title{
The effect of non-storm time substorms on the ring current dynamics
}

\author{
EunJin Jang, Chao Yue*, QiuGang Zong, SuiYan Fu, and HaoBo Fu \\ Institute of Space Physics and Applied Technology, Peking University, Beijing 100871, China
}

\begin{abstract}
Key Points:
- We examined the evolution of plasma pressure and number flux of various ions during non-storm time substorms.

- The flux of ions with various energies was enhanced at different $L$-shells during non-storm time super-substorms.

- Non-storm time super-substorms can make a significant contribution to the ring current.
\end{abstract}

Citation: Jang, E. J., Yue, C., Zong, Q. G., Fu, S. Y. and Fu, H. B. (2021). The effect of non-storm time substorms on the ring current dynamics. Earth Planet. Phys., 5(3), 251-258. http://doi.org/10.26464/epp2021032

\begin{abstract}
During geomagnetically active times such as geomagnetic storms, large amounts of energy can be released into the Earth's magnetosphere and change the ring current intensity. Previous studies showed that significant enhancement of the ring current was related to geomagnetic storms, while few studies have examined substorm effects on ring current dynamics. In this study, we examine the ring current variation during non-storm time (SYM- $\mathrm{H}>-50 \mathrm{nT})$ substorms, especially during super-substorms $(A E>1000 \mathrm{nT})$. We perform a statistical analysis of ring current plasma pressure and number flux of various ion species under different substorm conditions, based on Van Allen Probe observations. The plasma pressure and ion fluxes of the ring current increased dramatically during supersubstorms, while little change was observed for substorms with $A E<1000 \mathrm{nT}$. The results shown in this study indicate that a non-storm time super-substorm may also have a significant contribution to the ring current.
\end{abstract}

Keywords: super-substorms; ring current; ion fluxes

\section{Introduction}

The ring current contains mainly energetic ion species: hydrogen, helium, and oxygen, with an energy of several keV to several hundreds of keV, generated by the westward magnetic gradient and curvature drifts of these energetic ions. The location of the ring current is between $\sim 2-7 R_{E}$ (Earth radii) (e.g., Le et al., 2004; Yue C et al., 2018, 2019a; Sandhu et al., 2019). During quiet times, the main source of ring current particles is supplied by the ionosphere and the solar wind. While the main carriers of the ring current are protons $\left(\mathrm{H}^{+}\right)$(Daglis, 2006), oxygen $\left(\mathrm{O}^{+}\right)$contributes to the ring current significantly during geomagnetically active times (e.g., Hamilton et al., 1988; Korth et al., 2000; Fu SY et al., 2001; Kistler et al., 2016; Yue C et al., 2018, 2019a, 2020a; Huang Z et al., 2020). In addition, the ring current would decay when loss processes are dominant over the acceleration and source processes; ring current particles are continuously lost due to charge exchange and coulomb collisions, as well as wave-particle interactions (Fok et al., 1991; Yuan ZG et al., 2012; Yue C et al., 2019b, 2020b; Chen A et al., 2021). Three-dimensional ring current models were also constructed to investigate the variations of ring current ions (Fok et al., 1995; Jordanova et al., 1996).

Correspondence to: C. Yue, yuechao@pku.edu.cn

Received 02 JAN 2021; Accepted 15 APR 2021.

Accepted article online 29 APR 2021.

C 2021 by Earth and Planetary Physics.
The relationship between the ring current and geomagnetic storms has already been discussed extensively. During geomagnetic storms, the number of particles in the ring current increases and it becomes strongly intensified; Chapman and Ferraro (1941) described the formation of ring current during the storm's main phase. Greenspan and Hamilton (2002) estimated the relative contributions of $\mathrm{H}^{+}$and $\mathrm{O}^{+}$to the ring current energy density, close to the magnetic storm maximum. Daglis (2001) reviewed recent studies about the storm time ring current. According to previous studies, the storm-time substorm can also contribute to the ring current (e.g., Fok et al., 1999; Daglis et al., 2004; Boakes et al., 2011). The ions enter directly into the ring current during substorm injections, showing the large effect of ions on the ring current during storm-time substorms (Yue $\mathrm{C}$ et al., 2019a). It has been suggested that storm-time substorms had an effect on the rise of the $\mathrm{O}^{+} / \mathrm{H}^{+}$energy density ratio and also led to the increase of plasma sheet density (Nosé et al., 2005). By examining the $12 \mathrm{Au}$ gust 2000 storm event, Ohtani et al. (2005) inferred that ring current ions were de-energized during the growth phase and energetic particles were injected into the ring current during the expansion phase. Their result was the storm-time substorm contribution to the storm-time ring current intensification. Furthermore, Sandhu et al. (2018) conducted a statistical analysis of ring current energy variations with different substorm phases and spatial distributions, without distinguishing whether it occurred during storm time or non-storm time. It has been shown that there is a 
significant enhancement of ring current energy content in the substorm expansion phase, or in the premidnight magnetic local time (MLT) sector.

Previous works have shown the contribution of ions to the ring current during geomagnetic substorms (e.g., Sandhu et al., 2018), while no study has discussed the non-storm time substorms' contributions to the ring current. In this study, we focus on the dynamics of the ring current in non-storm time substorms. We perform a superposed analysis to examine the time evolution of plasma pressure and ion flux for different $L$-shells during nonstorm time substorms. We determine the contribution of nonstorm time substorms to the ring current and find that super-substorms with $A E>1000 \mathrm{nT}$ have a significant contribution to the ring current.

\section{Observation and Methods}

The Van Allen Probes (RBSP) consists of two identical satellites (A and B), launched on 30 August 2012 into a highly elliptical orbit, with perigee and apogee around $\sim 1.1 R_{\mathrm{E}}$ and $\sim 5.8 R_{\mathrm{E}}$, respectively (Mauk et al., 2013). In this study, we used the combined ion flux data of different species from the Helium, Oxygen, Proton, and Electron (HOPE) Mass Spectrometer (Funsten et al., 2013), and the Radiation Belt Storm Probes Ion Composition Experiment (RBSPICE) instrument (Mitchell et al., 2013). These are level 3 differential ion flux data. Using this combined database (Yue $\mathrm{C}$ et al., 2018), we get the proton $\left(\mathrm{H}^{+}\right)$, oxygen $\left(\mathrm{O}^{+}\right)$and helium $\left(\mathrm{He}^{+}\right)$ions energy flux from several $\mathrm{eV}$ to several hundred keV. More details about the data processing of ion flux can be found in Yue $C$ et al. (2018).

For this study, we used the total plasma pressure, which is calculated for the plasma pressure of different ions in the parallel and perpendicular directions using the unidirectional fluxes (Yue $C$ et al., 2018). The plasma pressure $\left(P_{i}\right)$ of different species is $P_{i}=\left(2 P_{\perp, i}+P_{\|, i}\right) / 3$ and the total plasma pressure $\left(P_{\mathrm{t}}\right)$ is the sum of the plasma pressures from different species, $P_{\mathrm{t}}=P_{\mathrm{H}^{+}}+$ $P_{\mathrm{O}^{+}}+P_{\mathrm{He}^{+}}+P_{\mathrm{e}^{-}}$. More details about the plasma pressure calculation can be found in Yue $C$ et al. (2018).

The substorm event list (Newell and Gjerloev, 2011a) from the years 2012 to 2018 is obtained from the SuperMAG database (Gjerloev, 2012), which defined a substorm using a simple automated algorithm to identify substorm expansion phase onsets from the SML index (the SuperMAG equivalent of the well-known $A L$ index). We used the substorm list of Newell and Gjerloev (2011a, 2011b) which can be downloaded from the SuperMAG website (https://supermag.jhuapl.edu/substorms/). The SuperMAG database is a collaboration of $\sim 110$ ground magnetometer stations. In order to assess the intensity of each substorm, we search for the maximum value of $A E$ index $\left(A E_{\max }\right)$ within $2 \mathrm{hr}$ after substorm onset. To identify the non-storm time substorm, we use the 1-min time resolution OMNI dataset of magnetic indices: Dst and $A E$ index. We require that the minimum $D s t$ index be larger than $-50 \mathrm{nT}$ for two hours prior and two hours after the substorm onset, to exclude the time interval of geomagnetic storms. We have a total of 1188 non-storm time substorm events with maximum $A E\left(A E_{\max }\right)$ values larger than $1000 \mathrm{nT}$ (super-substorms), and
5786 events with $A E_{\max }>300 \mathrm{nT}$ and $<1000 \mathrm{nT}$, respectively. In addition, we use the 1-min time resolution $S M R$ data from the SuperMAG database to show the ring current variations. SMR (Newell and Gjerloev, 2012) is a ring current index similar to Dst or SYM-H index. SMR also provides local time resolution of 4 sectors, to investigate local time dependence of the ring current during substorm events.

By using the list of non-storm time substorms, we performed a superposed epoch analysis of plasma pressures and different energies of ion fluxes for various species $\left(\mathrm{H}^{+}, \mathrm{O}^{+}, \mathrm{He}^{+}\right)$during nonstorm time substorms. Epoch time runs from two hours before to three hours after the substorm onset. The epoch time is divided into 5 -min bins, and $L$-shell is divided into $0.5 L$ bins from $L=2$ to 6 . To describe the pressure and flux variations before and after onset, each data point was normalized by the average value of two hours before substorm onset at each $0.5 \mathrm{~L}$-shell bin. Therefore, if a value is higher than 1 , it is colored red and means an enhancement at that time.

\section{Results}

Figure 1 illustrates the number flux variation of different ions observed by RBSP-A in one year, from 1 January to 31 December 2015. The top two panels show the daily-minimum value of the Dst index (Figure 1a) and the daily-maximum $A E$ index (Figure 1b). Figures $1(c-h)$ show the daily-averaged fluxes of various ions as labeled on the right of each panel using HOPE and RBSPICE from RBSP-A. We choose two representative energy channels of ring current for $\mathrm{H}^{+}, \mathrm{O}^{+}$, and $\mathrm{He}^{+}$ions, respectively. As the Dst and/or $A E$ increased, the flux of the ring current intensified. As shown in Figure 1 , the enhancement of ion fluxes is generally related to strong geomagnetic activity, especially during geomagnetic storm time. Besides the storm time enhancement of ion fluxes, there is also a comparable non-storm time increase of ion fluxes, as illustrated by the vertical blue shaded areas which mark the non-storm time super-substorm $\left(A E_{\max }>1000 \mathrm{nT}\right)$ cases. This demonstrates that the non-storm time substorm may also play an important role in increasing ring current intensity.

To examine the effects of substorms on the ring current, we provide in Figure 2 the superposed epoch results of plasma pressures of various ions for the non-storm time substorm events with $A E_{\max }>1000 \mathrm{nT}$ (1188 events) and $A E_{\max }<1000 \mathrm{nT}$ (5786 events). The left plots (Figure $2(\mathrm{a}-\mathrm{f})$ ) depict the statistical results of $A E_{\max }$ $>1000 \mathrm{nT}$, while the right plots (Figure $2(\mathrm{~g}-\mathrm{l})$ ) demonstrate the results of $A E_{\max }<1000 \mathrm{nT}$. The vertical dashed line marks the substorm onset time, while the plot time duration is from 2 hours before to 3 hours after the substorm onset. In Figure 2, we show the median value of $A E$ and the normalized plasma pressure variation as a function of epoch time and $L$-shell. Figure 2 ( $a$ and g) shows the satellite dwelling time (in minutes) in each bin and Figure 2 (b and $\mathrm{h}$ ) shows the $A E$ index distributions. As shown, the dwelling time at each bin is larger than 50 mins, which ensures statistical significance, although it is smaller at smaller $L$ shells. This is due to the fact that the spacecraft moves faster near perigee and slower near apogee. According to Figure 2 ( $b$ and $h$ ), the $A E$ index distributions are very similar at different $L$ shells and it is dramatically enhanced after substorm onset time, indicating that there is large 

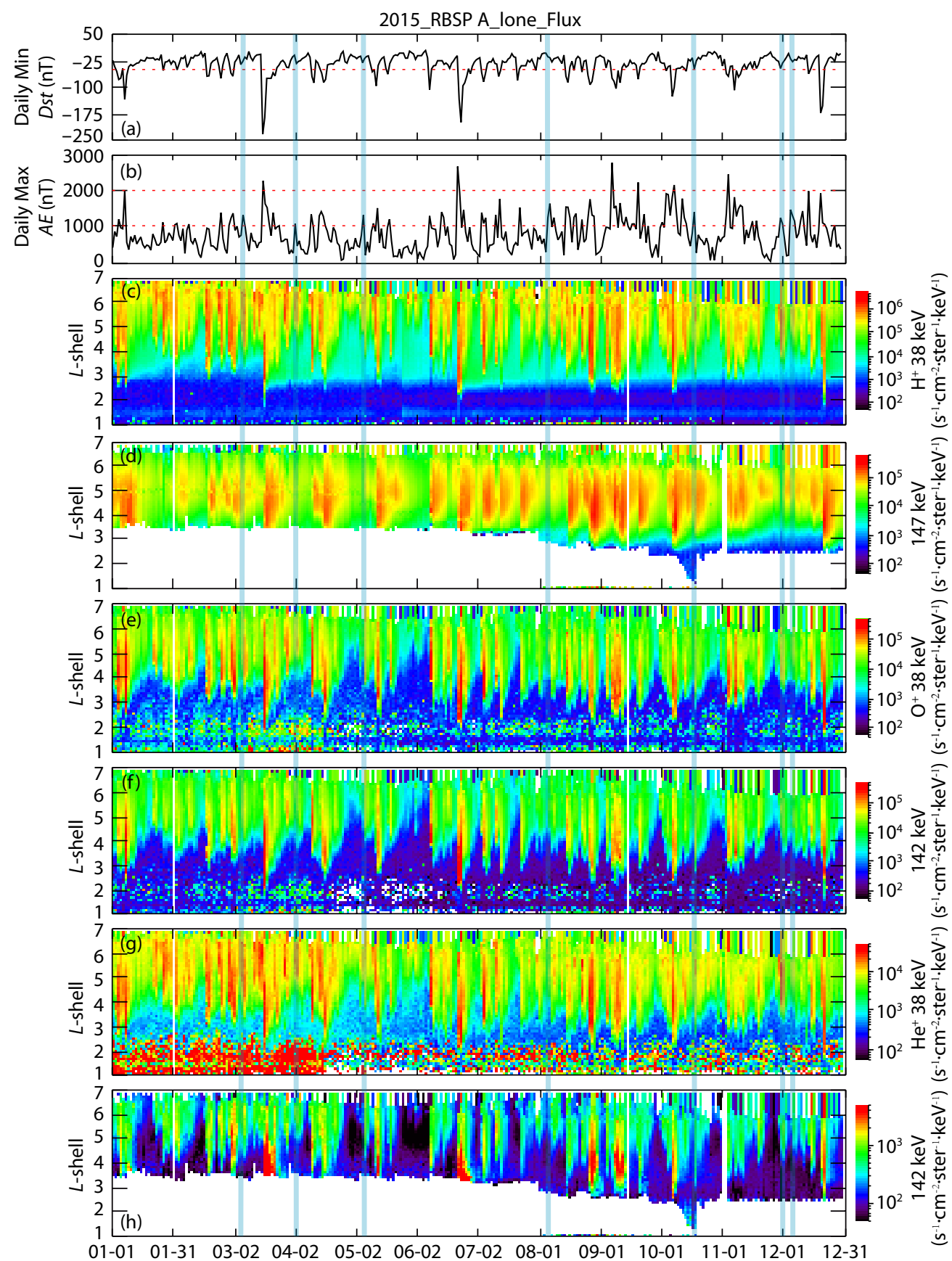

Figure 1. Daily minimum $D s t$ index (a), daily maximum $A E$ index (b), and daily averaged fluxes of energetic ions with different energies (c-h) from 1 January to 31 December 2015. The flux data from the HOPE and RBSPICE instruments on RBSP-A: (c) $38 \mathrm{keV} \mathrm{H}^{+}$, (d) $147 \mathrm{keV} \mathrm{H^{+ }}$, (e) $38 \mathrm{keV}$ $\mathrm{O}^{+}$, (f) $142 \mathrm{keV} \mathrm{O}^{+}$, (g) $38 \mathrm{keV} \mathrm{He}^{+}$, (h) $142 \mathrm{keV} \mathrm{He}^{+}$. Blue vertical lines denote the cases of non-storm time substorms.

amount of magnetic energy released after substorm onset.

Figure $2(\mathrm{c}-\mathrm{f})$ and Figure $2(\mathrm{i}-\mathrm{l})$ show the total plasma pressure and the plasma pressure of $\mathrm{H}^{+}, \mathrm{O}^{+}$and $\mathrm{He}^{+}$, respectively, during different substorm conditions. As shown, the plasma pressures were significantly enhanced in a large range of $L$-shells during the super-substorm $\left(A E_{\max }>1000 \mathrm{nT}\right)$ while almost no change is found for substorms with $A E_{\max }<1000 \mathrm{nT}$. During the super-substorms, the total plasma pressure and proton pressure increases immediately at $L=2-4$ after the substorm onset. Meanwhile, the oxygen and helium pressures show large enhancements after half an hour of super-substorm onset, demonstrating different transportation processes. After substorm onset, the oxygen pressure (Figure 2e) has increased about 1.5 times, while the changes of other ions' pressure are less than that of oxygen ions, resulting in a rapid increase of $\mathrm{O}^{+}$ring current during the substorm (Fok et al., 2006). On the other hand, the pressures show almost no enhancement after the substorm onset during $A E_{\max }<1000 \mathrm{nT}$ substorms. These features suggest that a large number of ions are injected when non-storm time super-substorms occur, as opposed to normal substorms $\left(A E_{\max }<1000 \mathrm{nT}\right)$. 

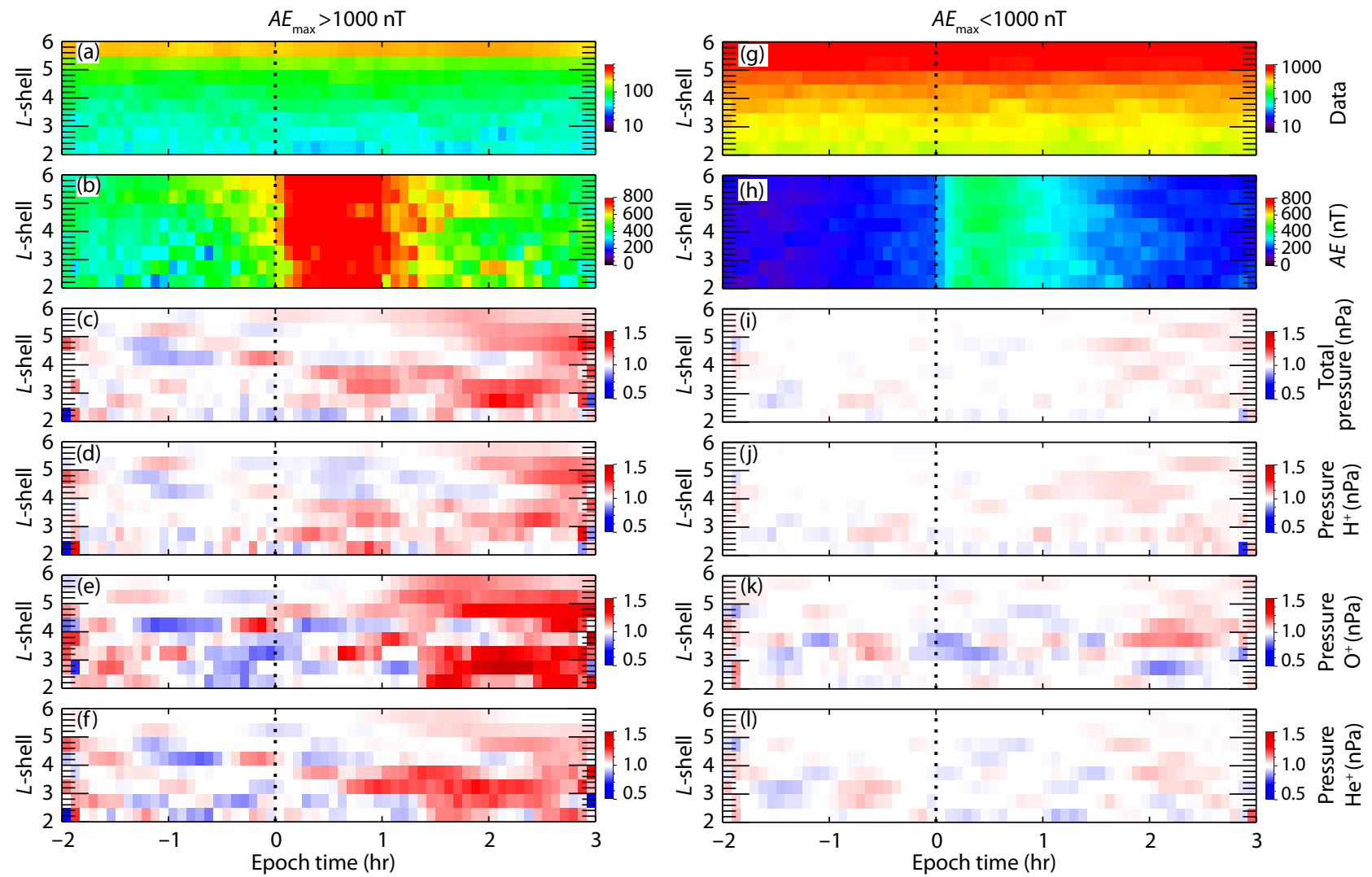

Figure 2. Superposed epoch analyses of the distribution of various ions' pressure with $L$-shell value during the cases of $A E_{\max }>1000 \mathrm{nT}$ (a) the number of data, (b) the $A E$ index, (c-f) total pressure and pressure of $\mathrm{H}^{+}, \mathrm{O}^{+}$and $\mathrm{He}^{+}$, respectively; ( $\mathrm{g}-\mathrm{h}$ ) plots show same data types but for $A E_{\text {max }}$ $<1000 \mathrm{nT}$. The dashed lines show the time of onset.
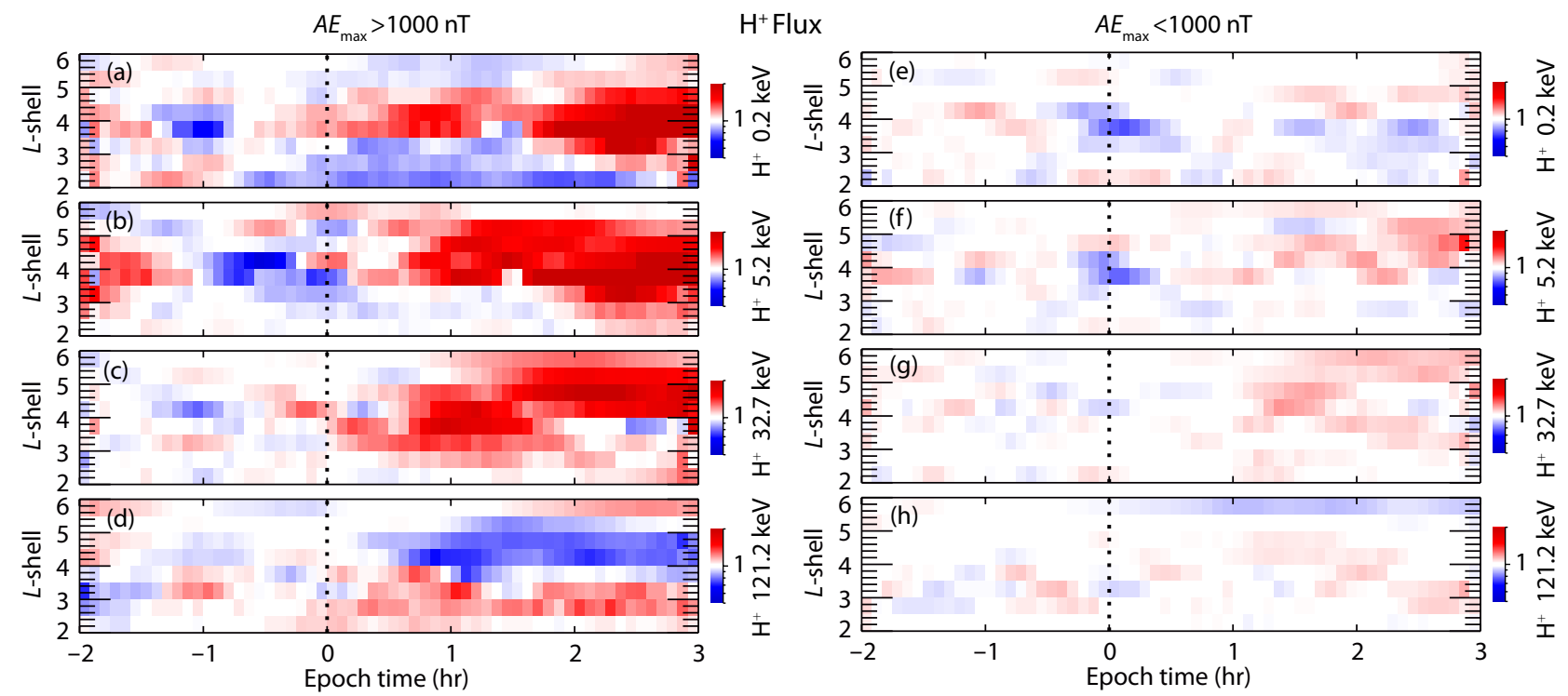

Figure 3. Normalized superposed epoch analyses of $\mathrm{H}^{+}$flux during $A E_{\max }>1000 \mathrm{nT}(\mathrm{a}-\mathrm{d})$ and $A E_{\max }<1000 \mathrm{nT}$ (e-h). (a and e) $0.2 \mathrm{keV}$, (b and f) $5.2 \mathrm{keV}$, (c and g) $32.7 \mathrm{keV}$, ( $\mathrm{d}$ and h) $121.2 \mathrm{keV} \mathrm{H}^{+}$, respectively. The dashed lines show the time of onset.

Figure 3 shows the superposed epoch results for normalized proton $\left(\mathrm{H}^{+}\right)$fluxes of different energies. Panels from top to bottom are for $0.2 \mathrm{keV}, 5.2 \mathrm{keV}, 32.7 \mathrm{keV}$, and $121.2 \mathrm{keV}$, respectively. The red color means that the flux is relatively higher than the average value for the two hours before onset at a specific $L$-shell. Figure 3 (a-d) shows the proton flux variation during super-substorms, whereas Figure $3(\mathrm{e}-\mathrm{h})$ is for normal substorms. During super-substorms, proton flux enhancement occurs immediately after the substorm onset. It is shown in Figure $3(a-d)$ that the different energy flux results from different enhancements in each $L$-shell dur- 
ing super-substorms: the $<1 \mathrm{keV}$ proton flux has strong enhancement in $L=3-5$ (Figure 3a) and a small decrease of flux at low $L$ shells; the several keV protons are significantly increased in $L>3$ (Figure $3 \mathrm{~b}$ ); while the tens of keV protons are significantly increased in a large range of $L$-shells (Figure $3 c$ ). In contrast, the high energy protons (Figure $3 d$ ) are increased in low $L$-shells $(L<$ 3 ) and decrease in high $L$ shells during super-substorms. Compared with Figure $3(\mathrm{a}-\mathrm{d})$, Figure $3(\mathrm{e}-\mathrm{h})$ show very small variation after the onset of substorms.

Figures 4 and 5 show the flux variation of oxygen $\left(\mathrm{O}^{+}\right)$and helium $\left(\mathrm{He}^{+}\right)$ions with the same format as Figure 3. We plotted the $\mathrm{O}^{+}$ flux of $1.1 \mathrm{keV}, 5.2 \mathrm{keV}, 38.1 \mathrm{keV}$ and $142 \mathrm{keV}$ in Figure 4, and the $\mathrm{He}^{+}$flux of $2.4 \mathrm{keV}, 5.2 \mathrm{keV}, 28.1 \mathrm{keV}$ and $142 \mathrm{keV}$ in Figure 5 . There are significant differences between super-substorms and normal substorms. During super-substorms, the low-energy oxygen ions (Figure $4(\mathrm{a}-\mathrm{c})$ ) show similar variation trends with the low energy protons. The oxygen ions with $1.1 \mathrm{keV}$ and $5.2 \mathrm{keV}$ first had the flux enhancement at $L>3.5$ and gradually enhanced towards the lower $L$-shells (Figure 4 ( $a$ and $b$ )). In contrast, the several tens of keV oxygen ions (Figure 4c) increased immediately at $L>$ 3 after the super-substorm onset. The flux in the higher energy channels (> $100 \mathrm{keV}$ ) started to increase across a large range of $L$ shells (Figure 4d). Compared with the case of super-substorms, the fluxes of different energy oxygen ions during normal substorms does not exhibit much change (Figure $4(\mathrm{e}-\mathrm{h})$ ). However, we found that the flux variation of helium is slightly different from the previous ions, shown in Figure 5. During super-substorms, the near $2 \mathrm{keV}$ helium increased after the substorm onset (Figure $5 \mathrm{a}$ ) and the several to tens of keV helium started to increase after

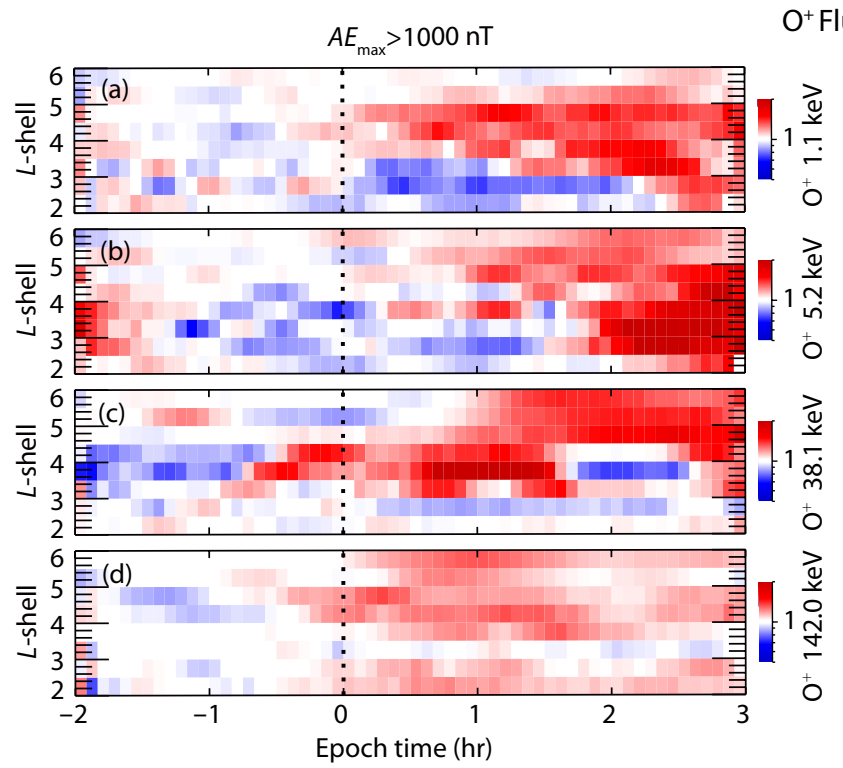

$\mathrm{O}^{+}$Flux

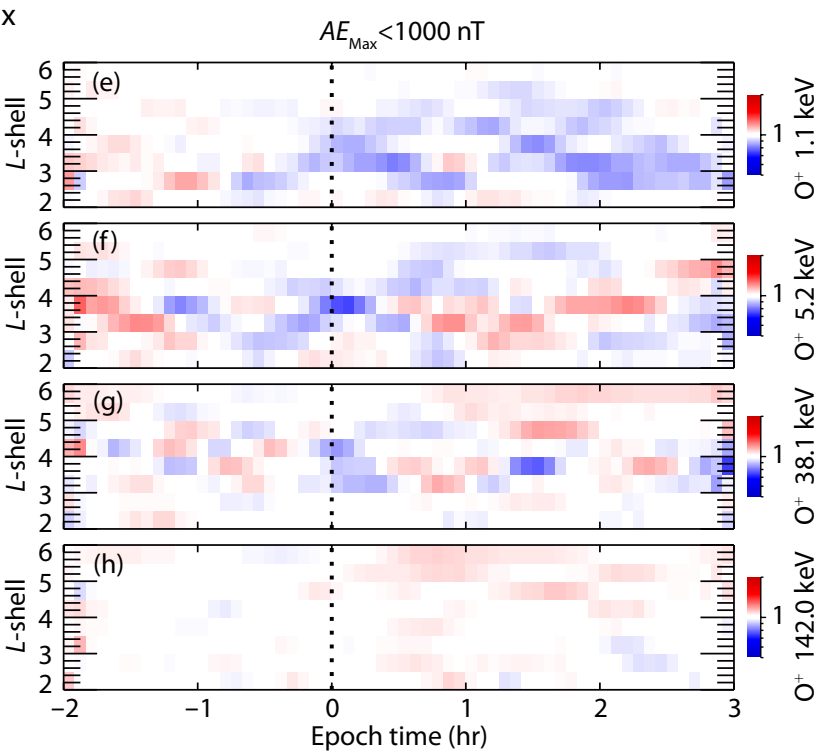

Figure 4. Similar format to Figure 3 for $\mathrm{O}^{+}$flux. (a and e) $1.1 \mathrm{keV}$, (b and f) $5.2 \mathrm{keV}$, (c and g) $38.1 \mathrm{keV}$, (d and h) 142.0 keV O+, respectively.
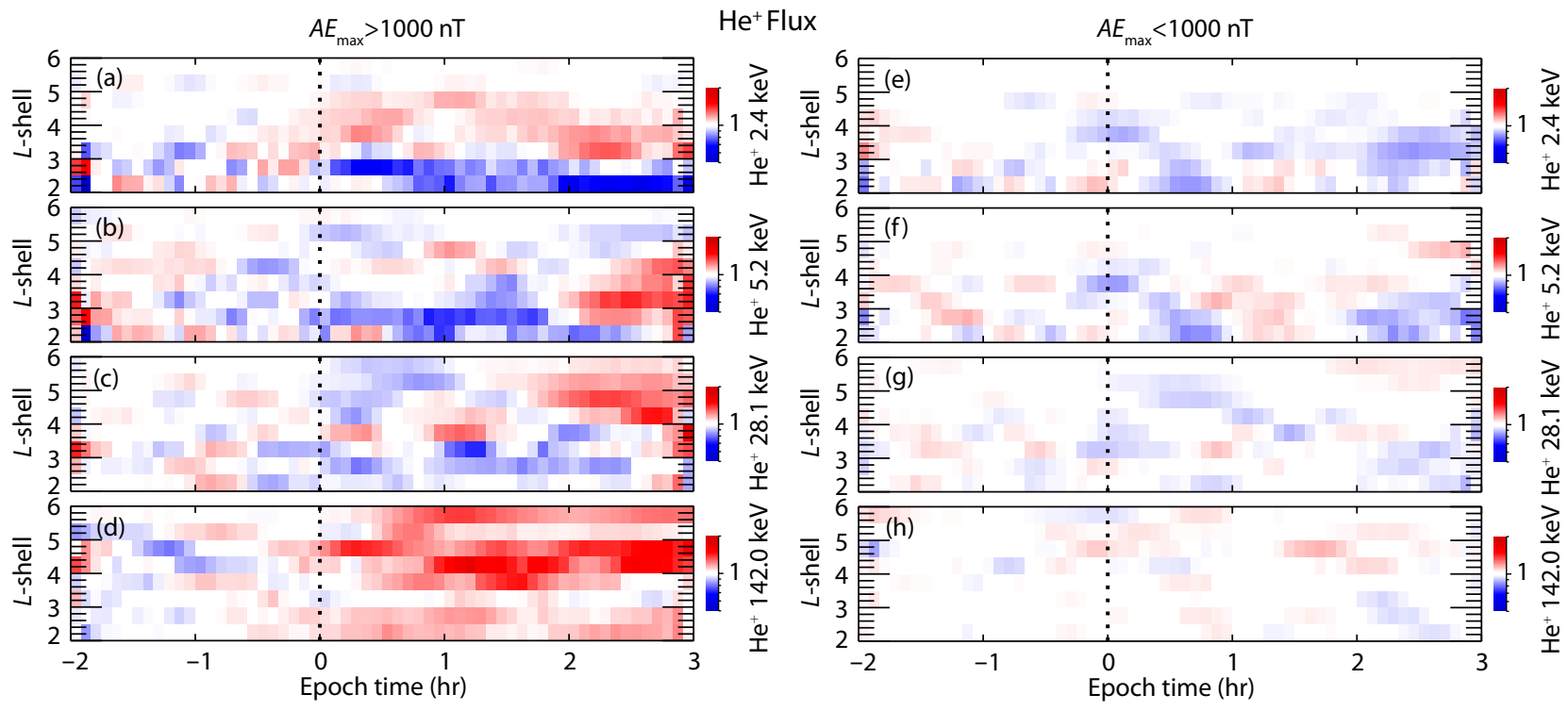

Figure 5. Similar format to Figure 3 for He flux. (a and e) $2.4 \mathrm{keV}$, (b and f) $5.2 \mathrm{keV}$, (c and g) $28.1 \mathrm{keV}$, (d and h) 142.0 keV He+, respectively. 
2 hours of onset (Figure 5 (b and c)). Further, similar to Figure $4 d$, the flux of $>100 \mathrm{keV}$ helium (Figure $5 \mathrm{~d}$ ) also increased after the onset for a large range of $L$-shells. Similar to the proton and oxygen flux variation, the helium fluxes are nearly unchanged during normal substorms. According to the above three Figures (3-5), when super-substorms occur, most of the energetic ions would be injected deep in the inner magnetosphere and contribute to the ring current enhancement.

Figure 6 shows the superposed epoch result of the SMR index obtained from SuperMAG, which represents the ring current intensity. Using SMR index, we show the local time variations of the ring current. The lines of different color denote the different local time sector with 0 LT (21-03) in pink, 6 LT (03-09) in blue, 12 LT (09-15) in light blue and 18 LT (15-21) in red. Figure 6 ( $a$ and b) show the statistical $S M R$ variations of $A E_{\max }>1000 \mathrm{nT}$ and $A E_{\max }<$ $1000 \mathrm{nT}$, respectively, following the standard features as demonstrated in Newell and Gjerloev (2012). After the substorm onset, the SMR index of $12 \mathrm{LT}$ and $18 \mathrm{LT}$ dropped while the SMR index of 0 LT increased, and the SMR index of 6 LT dropped the least in magnitude, indicating different variations of the ring current. However, there is a disparity in the magnitude of SMR variation between Figure $6 \mathrm{a}$ and Figure $6 \mathrm{~b}$. First, during super-substorms (Figure 6a), SMR of $0 \mathrm{LT}$ is smaller than $-10 \mathrm{nT}$ during the entire interval, although it had a rise of about $5 \mathrm{nT}$ after the substorm onset. Besides, SMR of 12 LT and 18 LT shifted more negative during super-substorms than during normal-substorms (Figure $6 \mathrm{~b}$ ). The largest change is at $18 \mathrm{LT}$ with $\triangle S M R$ of $8 \mathrm{nT}$ within $50 \mathrm{~min}$ after the super-substorm onset, while it is only $3 \mathrm{nT}$ within $50 \mathrm{~min}$ for normal substorms, indicating that the super-substorm may contribute to the ring current intensity significantly.

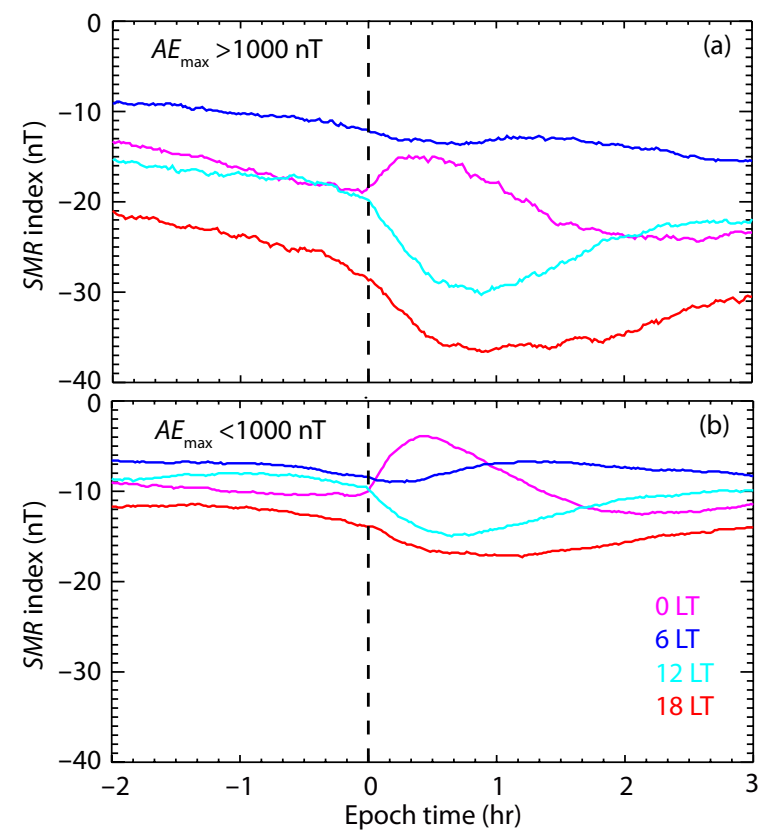

Figure 6. Superposed epoch analyses of $S M R$ index during the cases of $A E_{\max }>1000 \mathrm{nT}$ (a) and $A E_{\max }<1000 \mathrm{nT}$ (b). The different colors of lines show $0 \mathrm{LT}, 6 \mathrm{LT}, 12 \mathrm{LT}$ and $18 \mathrm{LT}$, respectively. The dashed lines show the time of onset.

\section{Discussion and Conclusions}

In this study, we have conducted a superposed epoch analysis of ring current fluxes and plasma pressures for three ion species during different conditions of non-storm time substorms, by using HOPE and RBSPICE measurements onboard the Van Allen Probe mission. Based on the SuperMAG substorm list from 2012 to 2018, we separated the non-storm time (SYM-H $>-50 \mathrm{nT})$ substorms into two categories, $A E_{\max }>1000 \mathrm{nT}$ and $A E_{\max }<1000 \mathrm{nT}$. $A E_{\max }$ denotes the maximum $A E$ index value within $2 \mathrm{hr}$ after substorm onset. The main results are as follows:

(1) The plasma pressures have significant enhancement after the super-substorm onset while there are almost no variations for substorms with $A E_{\max }<1000 \mathrm{nT}$.

(2) The flux of ions with various energies was enhanced at different $L$-shells during non-storm time super-substorms.

(3) The non-storm time super-substorms have a significant contribution to the ring current.

Compared with $A E_{\max }<1000 \mathrm{nT}$ of normal substorms, there are significant plasma pressure enhancements at a large range of $L$ shells during super-substorms. Especially, the oxygen pressure has the most significant variation, which suggests that the $\mathrm{O}^{+}$ions are related to the ring current during super-substorms (e.g., Ohtani et al., 2005; Nose' et al., 2005; Fok et al., 2006; Yue $C$ et al., 2019a; Zong QG et al., 2021), whereas, during normal substorms, the plasma pressures have no obvious changes.

The energy flux variations of various ion species have different characteristics across $L$-shells. The hundreds of eV to several tens of $\mathrm{keV}^{+}$and $\mathrm{O}^{+}$fluxes are enhanced by nearly double after super-substorm onset; in contrast, the $\mathrm{He}^{+}$flux with several tens of $\mathrm{keV}$ is strongly enhanced after 2 hours of super-substorm onset. Additionally, the enhancements of $\mathrm{O}^{+}$and $\mathrm{He}^{+}$flux with hundreds of keV are in all ranges of $L$-shells, meanwhile, $\mathrm{H}^{+}$flux is increased only in lower $L$-shells. In general, $\mathrm{O}^{+}$ions in the ring current are increased during active times (e.g., Hamilton et al., 1988). During geomagnetic storms, $\mathrm{O}^{+}$ions increase dramatically and there are two source regions of ring current $\mathrm{O}^{+}$ions. The lower energy $\mathrm{O}^{+}$ ions $(<1 \mathrm{keV})$ are from the dayside cusp and transported to the nightside plasma sheet, or they can access the inner magnetosphere through the nightside aurora region (e.g., Kistler et al., 2016). On the other hand, the tens of $\mathrm{keV} \mathrm{O}^{+}$ions may be directly from the plasma sheet (e.g., Hall et al., 1998). Modeling work has confirmed that the source regions of the energetic $\mathrm{O}^{+}$ions during substorms are also consistent with sources during storms (e.g., Nakayama et al., 2017). According to our results, $\mathrm{O}^{+}$ions are increased in high $L$-shells during non-storm time super-substorms, which means that the enhancement of $\mathrm{O}^{+}$ions originated from the plasma sheet and appeared in the ring current region due to super-substorm injection. According to the result of high energy ions, during super-substorms the peak of the ring current moved to lower L-shells; however, there is no significant change in the flux during normal substorms.

The magnitude of the decrease in SMR index during super-substorms is much larger ( $9.6 \mathrm{nT} / \mathrm{hr}$ ) than during normal substorms (3.6/hr). From Newell and Gjerloev (2012), we have found that the perturbation of SMR during geomagnetic storms is almost 11 
$\mathrm{nT} / \mathrm{hr}$. Therefore, the variation rate of SMR is comparable between geomagnetic storms and the non-storm time super-substorms, indicating that the latter also have a significant contribution to the ring current. This is due to the fact that, during super-substorms, there are more energetic particles that could be injected deeper into the inner magnetosphere, thus contributing more significantly to the ring current. In addition, during the super-substorms, the plasma pressure and fluxes are larger compared with normal substorms. Overall, the ions contribute to the ring current not only during storm time substorms but also during non-storm time super-substorms.

\section{Acknowledgments}

The study was supported by a research grant of China National Space Administration project D020303, NSFC Grant Numbers: 41974191 and the National Key R \& D Program of China 2020YFE0202100. We acknowledge use of Van Allen Probes data: Level 3 HOPE uni-dimensional particle flux data were obtained from the RBSP-ECT website (https://rbsp-ect.lanl.gov/data_pub/ rbspa/hope/level3/pitchangle/), made publicly available through NASA prime contract number NAS5-01072; Level 3 omni and unidimensional RBSPICE particle flux data were obtained from the RBSPICE website (http://rbspicea.ftecs.com/Level_3PAP/). We thank the Space Physics Data Facility at the NASA Goddard Space Flight Center for providing the OMNI data (https://cdaweb.gsfc. nasa.gov/index.html/). We gratefully acknowledge the substorm timing list identified by the Newell and Gjerloev technique (Newell and Gjerloev, 2011a), the SMU and SML indices (Newell and Gjerloev, 2011b); and the SuperMAG collaboration (https:// supermag.jhuapl.edu/info/?page=acknowledgement) (Gjerloev, 2012).

\section{References}

Boakes, P. D., Milan, S. E., Abel, G. A., Freeman, M. P., Chisham, G., and Hubert, B. (2011). A superposed epoch investigation of the relation between magnetospheric solar wind driving and substorm dynamics with geosynchronous particle injection signatures. J. Geophys. Res.: Space Physics, 116(A1), A01214. https://doi.org/10.1029/2010ja016007

Chapman, S., and Ferraro, V. C. A. (1941). The geomagnetic ring-current: I-Its radial stability. Terr. Magn. Atmos. Electr., 46(1), 1-6. https://doi.org/10.1029/TE046i001p00001

Chen, A., Yue, C., Chen, H. F., Zong, Q. G., Fu, S. Y., Wang, Y. F., and Ren, J. (2021). Ring current decay during geomagnetic storm recovery phase: Comparison between RBSP observations and theoretical modeling. J. Geophys. Res.: Space Physics, 126(1), e2020JA028500. https://doi.org/10.1029/2020JA028500

Daglis, I. (2001). The storm-time ring current. Space Sci. Rev., 98(3-4), 343-363. https://doi.org/10.1023/A:1013873329054

Daglis, I. A. (2006). Ring current dynamics. Space Sci. Rev., 124(1-4), 183-202. https://doi.org/10.1007/s11214-006-9104-z

Daglis, I. A., Delcourt, D., Metallinou, F. A., and Kamide, Y. (2004). Particle acceleration in the frame of the storm-substorm relation. IEEE Trans. Plasma Sci., 32(4), 1449-1454. https://doi.org/10.1109/tps.2004.831736

Fok, M. C., Kozyra, J. U., Nagy, A. F., and Cravens, T. E. (1991). Lifetime of ring current particles due to coulomb collisions in the plasmasphere. J. Geophys. Res. Space Physics, 96(A5), 7861-7867. https://doi.org/10.1029/90JA02620

Fok, M. C., Moore, T. E., Kozyra, J. U., Ho, G. C., and Hamilton, D. C. (1995). Threedimensional ring current decay model. J. Geophys. Res.: Space Physics., 100(A6), 9619-9632. https://doi.org/10.1029/94ja03029

Fok, M. C., Moore, T. E., and Delcourt, D. C. (1999). Modeling of inner plasma sheet and ring current during substorms. J. Geophys. Res.: Space Physics, 104(A7), 14557-14569. https://doi.org/10.1029/1999ja900014

Fok, M.-C., Moore, T. E., Brandt, P. C., Delcourt, D. C., Slinker, S. P., and Fedder, J. A. (2006). Impulsive enhancements of oxygen ions during substorms. J. Geophys. Res.: Space Physics., 111(A10), A10222. https://doi.org/10.1029/2006ja011839

Fu, S. Y., Wilken, B., Zong, Q. G., and Pu, Z. Y. (2001). Ion composition variations in the inner magnetosphere: Individual and collective storm effects in 1991. J. Geophys. Res.: Space Physics, 106(A12), 29683-29704. https://doi.org/10.1029/2000ja900173

Funsten, H. O., Skoug, R. M., Guthrie, A. A., MacDonald, E. A., Baldonado, J. R., Harper, R. W., Henderson, K. C., Kihara, K. H., Lake, J. E., ... Chen, J. (2013). Helium, Oxygen, Proton, and Electron (HOPE) mass spectrometer for the radiation belt storm probes mission. Space Science Reviews, 179(1-4), 423-484. https://doi.org/10.1007/s11214-013-9968-7

Gjerloev, J. (2012). The SuperMAG data processing technique. J. Geophys. Res.: Space Physics, 117(A9), A09213. https://doi.org/10.1029/2012JA017683

Greenspan, M. E., and Hamilton, D. C. (2002). Relative contributions of $\mathrm{H}^{+}$and $\mathrm{O}^{+}$to the ring current energy near magnetic storm maximum. J. Geophys. Res.: Space Physics, 107(A4), SMP 3-1-SMP 3-9. https://doi.org/10.1029/2001JA000155

Hall, A. M., Perry, C. H., Grande, M., Lester, M., and Wilken, B. (1998). Survey of dispersionless substorm ion injections observed by CRRES. Adv. Space Res., 21(4), 615-618. https://doi.org/10.1016/S0273-1177(97)00971-X

Hamilton, D. C., Gloeckler, G., Ipavich, F. M., Stüdemann, W., Wilken, B., and Kremser, G. (1988). Ring current development during the great geomagnetic storm of February 1986. J. Geophys. Res.: Space Physics., 93(A12), 14343-14355. https://doi.org/10.1029/JA093iA12p14343

Huang, Z., Yuan, Z. G., and Yu, X. D. (2020). Evolutions of equatorial ring current ions during a magnetic storm. Earth and Planetary Physics, 4(2), 131-137. https://doi.org/10.26464/epp2020019

Jordanova, V. K., Kistler, L. M., Kozyra, J. U., Khazanov, G. V., and Nagy, A. F. (1996). Collisional losses of ring current ions. J. Geophys. Res.: Space Physics, 101(A1), 111-126. https://doi.org/10.1029/95ja02000

Kistler, L. M., Mouikis, C. G., Spence, H. E., Menz, A. M., Skoug, R. M., Funsten, H. O., Larsen, B. A., Mitchell, D. G., Gkioulidou, M., ... Lanzerotti, L. J. (2016). The source of $\mathrm{O}^{+}$in the storm time ring current. J. Geophys. Res.: Space Physics, 121(6), 5333-5349. https://doi.org/10.1002/2015JA022204

Korth, A., Friedel, R. H. W., Mouikis, C. G., Fennell, J. F., Wygant, J. R., and Korth, H. (2000). Comprehensive particle and field observations of magnetic storms at different local times from the CRRES spacecraft. Journal of Geophysical Research: Space Physics, 105(A8), 18729-18740. https://doi.org/10.1029/1999JA000430

Le, G., Russell, C. T., and Takahashi, K. (2004). Morphology of the ring current derived from magnetic field observations. Ann. Geophys., 22(4), 1267-1295. https://doi.org/10.5194/angeo-22-1267-2004

Mauk, B. H., Fox, N. J., Kanekal, S. G., Kessel, R. L., Sibeck, D. G., and Ukhorskiy, A. (2013). Science objectives and rationale for the Radiation Belt Storm Probes mission. Space Sci. Rev., 179(1-4), 3-27. https://doi.org/10.1007/s11214-0129908-y

Mitchell, D. G., Lanzerotti, L. J., Kim, C. K., Stokes, M., Ho, G., Cooper, S., Ukhorskiy, A., Manweiler, J. W., Jaskulek, S., ... Brown, L. E. (2013). Radiation belt storm probes ion composition experiment (RBSPICE). Space Sci. Rev., 179(1-4), 263-308. https://doi.org/10.1007/978-1-4899-7433-4_8

Nakayama, Y., Ebihara, Y., Fok, M., and Tanaka, T. (2017). Impact of substorm time $\mathrm{O}^{+}$outflow on ring current enhancement. J. Geophys. Res.: Space Physics, 122(6), 6304-6317. https://doi.org/10.1002/2016JA023766

Newell, P. T., and Gjerloev, J. W. (2011a). Evaluation of SuperMAG auroral electrojet indices as indicators of substorms and auroral power. J. Geophys. Res.: Space Physics, 116(A12), A12211.

https://doi.org/10.1029/2011JA016779

Newell, P. T., and Gjerloev, J. W. (2011b). Substorm and magnetosphere characteristic scales inferred from the SuperMAG auroral electrojet indices. J. Geophys. Res.: Space Physics, 116(A12). https://doi.org/10.1029/2011JA016936

Newell, P. T., and Gjerloev, J. W. (2012). SuperMAG-based partial ring current 
indices. J. Geophys. Res.: Space Physics, 117(A5), A05215. https://doi.org/10.1029/2012ja017586

Nosé, M., Taguchi, S., Hosokawa, K., Christon, S. P., McEntire, R. W., Moore, T. E., and Collier, M. R. (2005). Overwhelming $\mathrm{O}^{+}$contribution to the plasma sheet energy density during the October 2003 superstorm: Geotail/EPIC and IMAGE/LENA observations. J. Geophys. Res.: Space Physics, 110(A9), A09S24. https://doi.org/10.1029/2004ja010930

Ohtani, S., Brandt, P. C., Mitchell, D. G., Singer, H., Nosé, M., Reeves, G. D., and Mende, S. B. (2005). Storm-substorm relationship: Variations of the hydrogen and oxygen energetic neutral atom intensities during storm-time substorms. J. Geophys. Res.: Space Physics, 110(A7), A07219. https://doi.org/10.1029/2004JA010954

Sandhu, J. K., Rae, I. J., Freeman, M. P., Forsyth, C., Gkioulidou, M., Reeves, G. D., Spence, H. E., Jackman, C. M., and Lam, M. M. (2018). Energization of the ring current by substorms. J. Geophys. Res.: Space Phys., 123(10), 8131-8148. https://doi.org/10.1029/2018JA025766

Sandhu, J. K., Rae, I. J., Freeman, M. P., Gkioulidou, M., Forsyth, C., Reeves, G. D., Murphy, K. R., and Walach, M.-T. (2019). Substorm-ring current coupling: A comparison of isolated and compound substorms. J. Geophys. Res.: Space Physics, 124(8), 6776-6791. https://doi.org/10.1029/2019ja026766

Yuan, Z. G., Xiong, Y., Wang, D. D., Li, M., Deng, X. H., Yahnin, A. G., Raita, T., and Wang, J. F. (2012). Characteristics of precipitating energetic ions/electrons associated with the wave-particle interaction in the plasmaspheric plume. J. Geophys. Res.: Space Physics, 117(A8), A08324. https://doi.org/10.1029/2012JA017783

Yue, C., Bortnik, J., Li, W., Ma, Q. L., Gkioulidou, M., Reeves, G. D., Wang, C. P.,
Thorne, R. M., Lui, A. T. Y., ... Mitchell, D. G. (2018). The composition of plasma inside geostationary orbit based on Van Allen Probes observations. J. Geophys. Res.: Space Physics, 123(8), 6478-6493. https://doi.org/10.1029/2018JA025344

Yue, C., Bortnik, J., Li, W., Ma, Q. L., Wang, C. P., Thorne, R. M., Lyons, L., Reeves, G. D., Spence, H. E., ... Mitchell, D. G. (2019a). Oxygen ion dynamics in the Earth's ring current: Van Allen Probes observations. J. Geophys.Res.: Space Physics, 124(10), 7786-7798. https://doi.org/10.1029/2019ja026801

Yue, C., Jun, C. W., Bortnik, J., An, X., Ma, Q. L., Reeves, G. D., Spence, H. E., Gerrard, A. J., Gkioulidou, M., ... Kletzing, C. A. (2019b). The relationship between EMIC wave properties and proton distributions based on Van Allen Probes observations. Geophys. Res. Lett., 46(8), 4070-4078. https://doi.org/10.1029/2019GL082633

Yue, C., Bortnik, J., Zou, S., Nishimura, Y., Foster, J. C., Coppeans, T., Ma, Q, L., Zong, Q. G., Hull, A. J., ... Spence, H. E. (2020a). Episodic occurrence of fieldaligned energetic ions on the dayside. Geophysical Research Letters, 47(2), e2019GL086384. https://doi.org/10.1029/2019GL086384

Yue, C., Ma, Q. L., Jun, C. W., Bortnik, J., Zong, Q. G., Zhou, X. Z., Jang, E. J., Reeves, G. D., Spence, H. E., Wygant, J. R. (2020b). The modulation of plasma and waves by background electron density irregularities in the inner magnetosphere. Geophysical Research Letters, 47(15), e2020GL088855. https://doi.org/10.1029/2020GL088855

Zong, Q.-G., Yue, C., and Fu, S. Y. (2021). Shock induced strong substorms and super substorms: Preconditions and associated oxygen ion dynamics. Space Science Reviews, 217(2), 33. https://doi.org/10.1007/s11214-021-00806-x 